\title{
Implications of open circuit voltage of light-emitting diodes installed for plant cultivation
}

\author{
Akira YANO $^{\mathrm{a}, \uparrow}$, Ryo MATSUDA $^{\mathrm{b}}$ and Kazuhiro FUJIWARA ${ }^{\mathrm{b}}$ \\ $\left(\begin{array}{c}{ }^{a} \text { Institute of Environmental Systems Science, Shimane University, } 1060 \text { Nishikawatsu, Matsue, Shimane 690-8504, Japan } \\ { }^{b} \text { Graduate School of Agricultural and Life Sciences, The University of Tokyo, 1-1-1 Yayoi, Bunkyo-ku, Tokyo 113-8657, Japan }\end{array}\right)$
}

\begin{abstract}
This study investigated a light sensor function of light-emitting diodes (LEDs), the use of which is expanding in plant cultivations. Unimodal spectral LEDs of four types with respective emission peak wavelengths of 464, 501, 634, and $849 \mathrm{~nm}$, and a white LED with a bimodal spectrum with 455-nm primary and 574-nm secondary peaks were used for this study. Open circuit voltage $\left(V_{\mathrm{OC}}\right)$ of up to $1-2 \mathrm{~V}$ was induced in the LEDs when they were irradiated with sunlight. The $V_{\mathrm{OC}}$ value of the $634 \mathrm{~nm}$ LED saturated with a low photon flux density can be used for binary discrimination between daylight and night. Each LED had a $V_{\text {OC }}$ inducible threshold wavelength of incident light. By virtue of the wavelength threshold feature, existence of a plant leaf between a light source and the LEDs is detectable by comparing the $V_{\mathrm{OC}}$ values of blue-green range LEDs $(464 \mathrm{~nm}, 501 \mathrm{~nm})$ and near-infrared (NIR) LEDs $(849 \mathrm{~nm})$. Under leaf shadow, the NIR LED $V_{\mathrm{OC}}$ exceeded those of the blue-green range LEDs. Under natural incident sunlight, the $V_{\mathrm{OC}} \mathrm{s}$ of the blue-green range LEDs were greater than that of the NIR LED. Another function of LEDs in agricultural use has been demonstrated.
\end{abstract}

Key words: Greenhouse, Photodiode, Photovoltaic effect, Plant factory, Vertical farming

\section{Introduction}

Plant cultivation studies conducted in experimental chambers using light-emitting diodes (LEDs) as the sole lighting source have been continued (Bula et al., 1991; Massa et al., 2008) since lettuce cultivation using red LEDs was planned for feeding astronauts fresh vegetables in a spacecraft (Kliss and MacElroy, 1990). The realization of blue LEDs (Akasaki et al., 1993; Nakamura et al., 1993), which enable emissions at the shorter wavelength peak of bimodal absorption spectra of chlorophylls, supported the role of LEDs as a light source for plant cultivation (Hernándes and Kubota, 2016; Matsuda et al., 2004). Subsequent declines of LED prices have led to commercial crop cultivation in closed, environmentally controlled facilities known as vertical farms (Benke and Tomkins, 2017; O'Sullivan et al., 2019) and plant factories with artificial lighting (Kozai, 2013; Kozai et al., 2020), which use numerous LEDs as light sources to drive photosynthesis, resulting in overwhelmingly high planting density, high growth rates, and high crop quality (Orsini et al., 2020). Field and greenhouse cultivations also use LEDs for purposes such as supplemental lighting for photosynthesis support (Deram et al., 2014; Hikosaka et al., 2013), photomorphogenesis modification (Cope and Bugbee, 2013; Jeong et al., 2014), metabolite synthesis activation (Kitazaki et al., 2018; Kopsell et al., 2014; Piovene et al., 2015), and pest management (Cochard et al., 2019; Stukenberg et al., 2015). In addition to visible light

Received; July 19, 2021

Accepted; October 12, 2021

†Corresponding author: yano@life.shimane-u.ac.jp

DOI: 10.2480/agrmet.D-21-00040 under the CC BY 4.0 license. of the 400-700 nm wavelength range required for maintenance of the basic physiology of plants, far-red (Shibuya et al., 2019; Zhang and Runkle, 2019) for photomorphogenesis and ultraviolet light (Huché-Thélier et al., 2016) for metabolite synthesis are wavelength bands that improve crop quality.

In contrast to the original role of light emission, a photovoltaic effect is induced in an LED when light is illuminated onto the semiconductor die which usually converts the changes in electron energy levels into light (Filippo et al., 2017; RayChaudhuri and Sen, 2009; Vannacci et al., 2018; Vannacci et al., 2019). Taking advantage of the photovoltaic feature, atmospheric turbidity and precipitable water measurements (Mims, 1992), atmospheric optical depth measurements (Acharya et al., 1995), solar photometry and surface reflectance measurements (RayChaudhuri and Sen, 2009), power delivery and data transmission in a wireless and battery-less microsystem (Haydaroglu and Mutlu, 2015), distance and image sensors (Vannacci et al., 2019), and a vegetation monitoring sensor (Kim et al., 2019; Ryu et al., 2010) have been realized using LEDs. The reported benefits of using LEDs as light sensors over photodiodes are affordability (Acharya et al., 1995; Mims, 1992; RayChaudhuri and Sen, 2009; Ryu et al., 2010), small size (Acharya et al., 1995; Mims, 1992; RayChaudhuri and Sen, 2009; Ryu et al., 2010), sturdiness (Acharya et al., 1995; Mims, 1992; RayChaudhuri and Sen, 2009), wavelength band selectivity (Filippo et al., 2017; RayChaudhuri and Sen, 2009; Ryu et al., 2010; Vannacci et al., 2018; Vannacci et al., 2019), and duality as an emitter and as a receiver (Vannacci et al., 2018; Vannacci et al., 2019).

This study examined whether the photovoltaic effects might be used for monitoring light information in plant-cultivation environments. If some useful information could be acquired, then turned-off LEDs could also be used effectively as sensors for plant-cultivation management. LEDs can be installed proximately to plants (Morrow, 2008) because of their characteristics of low heat radiation and small package size (Schubert and Kim, 2005). For this 

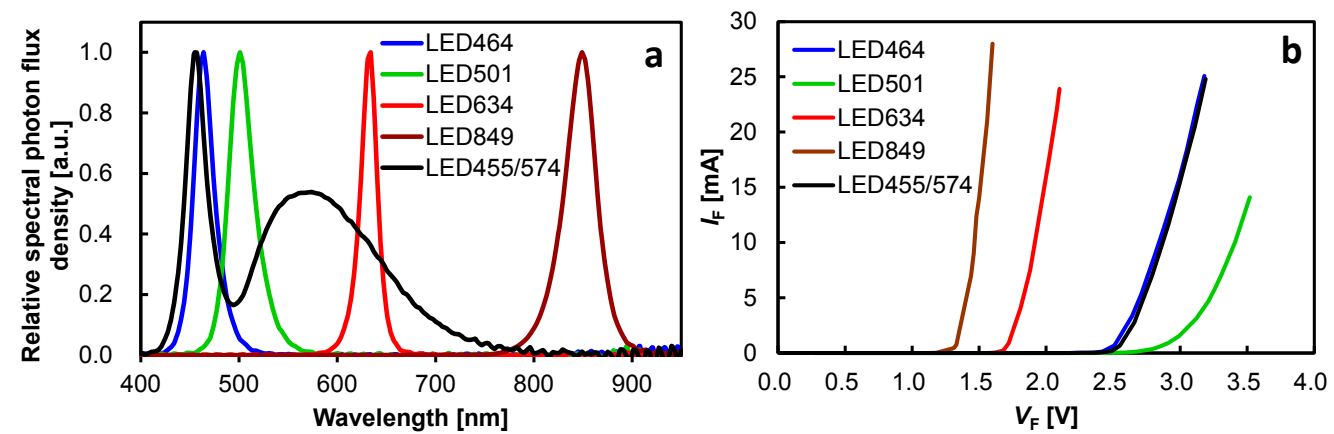

Fig. 1. Relative spectral photon flux densities (a) emitted from 5-mm-diameter LEDs respectively represented as $L_{E D} D_{464}$, $\mathrm{LED}_{501}, \mathrm{LED}_{634}, \mathrm{LED}_{849}$, and $\mathrm{LED}_{455 / 574}$ and forward voltage $V_{\mathrm{F}}$ - current $I_{\mathrm{F}}$ characteristics during light emission (b).

reason, LEDs can be installed not only on the ceilings and walls of horticultural facilities but also inside crop canopies (Joshi et $a l ., 2019)$. If LEDs could be used as light sensors, then acquisition of light distribution information (Ibaraki and Shigemoto, 2013) over a large plantation might become possible. Moreover, an LED might be used as a sensor for acquiring plant information related to optical parameters such as vegetation density.

For this study, open circuit voltages of unimodal spectral LEDs of four types with respective emission peak wavelengths of 464 , 501,634 , and $849 \mathrm{~nm}$ were investigated when they were irradiated by other external lighting sources. Those LED lights cover the radiation wavelength ranges necessary for plant growth and development. In addition, the open circuit voltage of a white LED with a bimodal spectrum with a primary sharp peak of $455 \mathrm{~nm}$ and broad secondary peak of $574 \mathrm{~nm}$ was tested. First, we investigated the wavelength range of incident light that induces an open circuit voltage in the five types of LED. Next, the open circuit voltages of the LEDs irradiated with sunlight were measured. Finally, the open circuit voltages induced in the LEDs by incident light transmitted through plant leaves were investigated. Based on these data, we propose to use LEDs, which are usually used as a light source for plant cultivation practices, as light sensors that provide light environment information useful for plant cultivation management.

\section{Materials and methods}

\subsection{LED photovoltaic effects induced by impinging unimodal spectral light}

Bullet-shaped, 5-mm-diameter LEDs of five types were assumed to be used as a light source for plant cultivation. Although LED package types have some variations, including surface-mount type which has been distributed commonly in plant cultivation practices, bullet-shaped LEDs were chosen for this study because their electrodes have ease of connectivity with test cables and test bread boards. Their performance as light sensors was tested to elucidate a new role of LEDs when they are turned off. Emission spectra of the five LED types were measured using a spectroradiometer (MS720, Eko Instruments Co., Ltd., Tokyo, Japan) (Fig. 1a). The wavelengths $\lambda_{\mathrm{PR}} \mathrm{s}$, which represent the peaks of unimodal spectral photon flux density (SPFD) of four LED types were, respectively, $464 \mathrm{~nm}$ (NSPB510AS; Nichia Corp., Tokushima, Japan), 501 nm (NSPE510DS; Nichia), 634 nm (NSPR510CS; Nichia), and 849 nm (TSHG8400; Vishay Intertechnology Asia Pte. Ltd., Tampines, Singapore). The bimodal spectral peaks of a white LED (NSPW510DS-D1; Nichia) were

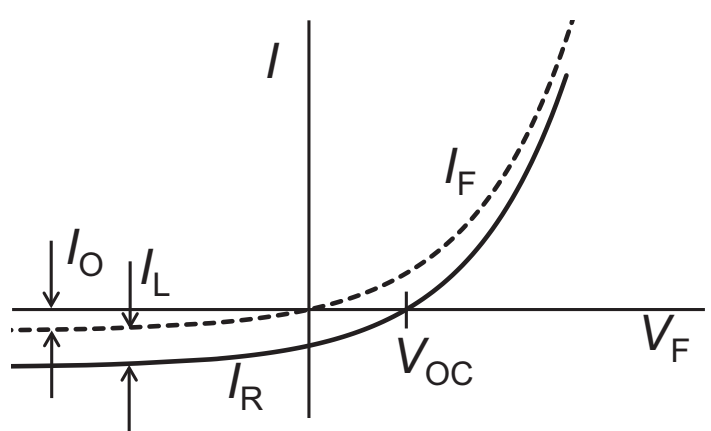

Fig. 2. Conceptual diagram of current-voltage characteristics of a p-n junction semiconductor.

$I_{\mathrm{F}}, I_{\mathrm{O}}, I_{\mathrm{L}}, I_{\mathrm{R}}$, and $V_{\mathrm{OC}}$ respectively represent the forward current, saturated dark current when a reverse voltage is applied, the generated current that flows through the semiconductor by light irradiation, current that flows in the opposite direction when the semiconductor is irradiated with light, and the open circuit voltage induced by light irradiation.

a $455 \mathrm{~nm}$ primary peak and a $574 \mathrm{~nm}$ secondary broad peak. Using the values of these emission peak wavelengths, the five LED types are represented as $\mathrm{LED}_{464}, \mathrm{LED}_{501}, \mathrm{LED}_{634}, \mathrm{LED}_{849}$, and $\mathrm{LED}_{455 / 574}$. Figure $1 \mathrm{~b}$ depicts the forward voltage $V_{\mathrm{F}}-$ current $I_{\mathrm{F}}$ characteristics of the five LED types. The $\mathrm{LED}_{634}$ and $\mathrm{LED}_{849}$, which emit longer wavelength radiation, have $I_{\mathrm{F}}$ increment at $V_{\mathrm{F}} \mathrm{S}$ of less than $2 \mathrm{~V}$, whereas $\mathrm{LED}_{455 / 574}, \mathrm{LED}_{464}$, and $\mathrm{LED}_{501}$, which emit shorter wavelength radiation, have $I_{\mathrm{F}}$ increment at $V_{\mathrm{F}} \mathrm{S}$ of greater than $2 \mathrm{~V}$. The relation between $V_{\mathrm{F}}$ and $I_{\mathrm{F}}$ of an ideal p-n junction diode is given as

$$
I_{\mathrm{F}}=I_{\mathrm{O}}\left\{\exp \left(\frac{q V_{\mathrm{F}}}{k T}\right)-1\right\}
$$

by the Shockley equation (Shockley, 1949), where $I_{\mathrm{O}}$ is the magnitude of saturated dark current when a reverse voltage is applied to the diode (Fig. 2) and where $q, k$, and $T$ respectively represent the unit charge amount, Boltzmann constant, and thermodynamic temperature. When the diode is irradiated with light to induce photovoltaic power, current $I_{\mathrm{R}}$ flowing in the opposite direction to $I_{\mathrm{F}}$ becomes

$$
I_{\mathrm{R}}=I_{\mathrm{L}}-I_{\mathrm{F}}=I_{\mathrm{L}}-I_{\mathrm{O}}\left\{\exp \left(\frac{q V_{\mathrm{F}}}{k T}\right)-1\right\}
$$

by taking the $I_{\mathrm{R}}$ direction as positive (Cuevas et al., 2000). In that equation, $I_{\mathrm{L}}$ is the generated current flowing through the 
p-n junction semiconductor by means of light irradiation. $I_{\mathrm{L}}$ is proportional to both the number of photons $N$ having $V_{\mathrm{OC}}$ inducible wavelengths and the surface area $A$ of the p-n junction semiconductor die receiving the light (Cuevas et al., 2000). Therefore, accurate light-sensing applications of $\mathrm{p}-\mathrm{n}$ junction semiconductors usually monitor $I_{\mathrm{L}}$ values (RayChaudhuri and Sen, 2009). However, the $I_{\mathrm{L}}$ values generated in an LED are too diminutive to be measured using conventional and reasonable instruments. The application purpose of this study is to use photovoltaic effects of neumerous turned-off LEDs already installed ubiquitously around crops to obtain light information across the plantation. Therefore, measurement of LED voltage is more practical than that of photo-generated current. According to equation 2, the open circuit voltage $V_{\mathrm{OC}}$ between the LED electrodes at $I_{\mathrm{R}}=0$ with incident light becomes

$$
0=I_{\mathrm{L}}-I_{\mathrm{O}}\left\{\exp \left(\frac{q V_{\mathrm{OC}}}{k T}\right)-1\right\}
$$

and thereby

$$
V_{\mathrm{OC}}=\frac{k T}{q} \ln \left(\frac{I_{\mathrm{L}}}{I_{\mathrm{O}}}+1\right)
$$

(Cuevas et al., 2000; Shockley, 1949). Using coefficients $a$ and $b$, equation 4 can be rewritten according to the following equation as the relation between the photon flux density and $V_{\mathrm{OC}}$ that can be measured by the growers using conventional instruments.

$$
V_{\mathrm{OC}}=a \ln \left(b E_{\mathrm{eff}}+1\right)
$$

In that equation, $E_{\text {eff }}$ is the photon flux density in the $V_{\mathrm{OC}}$ inducible wavelength range. The photon to voltage conversion characteristics of $\mathrm{LED}_{464}, \mathrm{LED}_{501}, \mathrm{LED}_{634}, \mathrm{LED}_{849}$, and $\mathrm{LED}_{455 / 574}$ can be expressed using equation 5 with experimentally obtained coefficients $a$ and $b$.

To find the coefficients $a$ and $b$, we conducted an experiment in which the five type LEDs were irradiated with unimodal spectral artificial light from outside using various other type LEDs. In a dark room, 3-mm-diameter bullet-shaped LEDs of 17 types (Epitex Inc., Kyoto, Japan), respectively having specific wavelength $\lambda_{\mathrm{PE}}$ at each radiation peak were placed respectively close to the spectroradiometer. The emitted SPFD was measured when each maximum rated forward current was applied to the respective 17 LEDs. One of the $3 \mathrm{~mm}$ LEDs of 17 types, as an emitter, was faced to one of the $5 \mathrm{~mm}$ LEDs as a light receiver. The $V_{\mathrm{OC}}$ induced in the $5 \mathrm{~mm}$ LED was measured (34401A; Agilent Technologies Inc., California, USA) when the $3 \mathrm{~mm}$ LED emitted light (Fig. 3).

\subsection{LED photovoltaic effects induced by impinging sunlight}

Assuming that LEDs are used for outdoor and greenhouse cultivations, $V_{\mathrm{OC}} \mathrm{S}$ of the $5 \mathrm{~mm}$ type LEDs irradiated with sunlight were measured. During 9:00-12:00 on 20 October 2020, $\mathrm{LED}_{464}, \mathrm{LED}_{501}, \mathrm{LED}_{634}, \mathrm{LED}_{849}$, and $\mathrm{LED}_{455 / 574}$ were fixed toward the zenith on the rooftop of a building of Shimane University Matsue Campus. The $V_{\mathrm{OC}}$ values of each type LED were measured at $30 \mathrm{~s}$ intervals using a data acquisition unit (34972A; Keysight Technologies Inc., California, USA). Sunlight SPFD of wavelengths of 350-1050 nm and

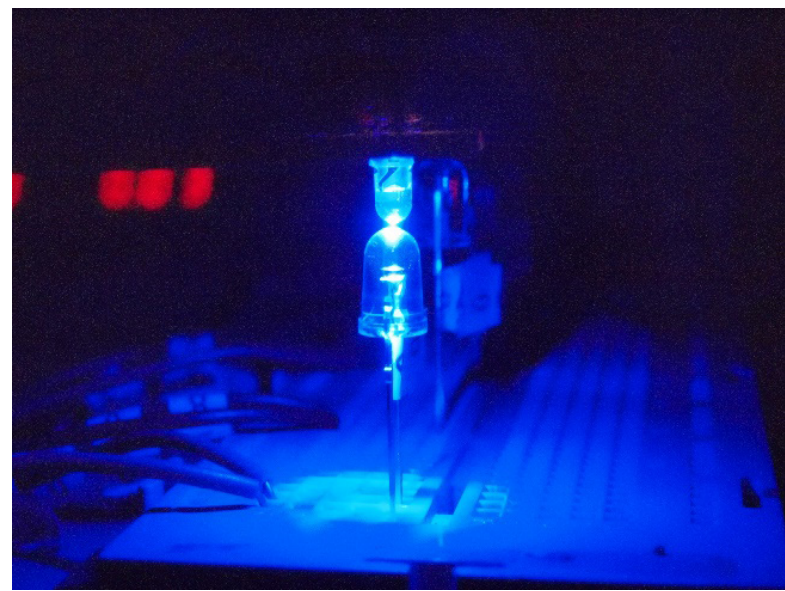

Fig. 3. Three-millimeter diameter LED on the top as the light emitter and 5-mm-diameter LED on the bottom as the receiver facing each other.

photosynthetic photon flux density (PPFD) in the 400-700 nm wavelength range were also measured at $30 \mathrm{~s}$ intervals using the spectroradiometer. The sky condition was fine. Assuming that LEDs are installed near crops, the LEDs are expected to receive light that has been transmitted through plant leaves or which was reflected by leaves. To test $V_{\mathrm{OC}}$ responses under such conditions, one leaf blade of lettuce (Lactuca sativa) was placed over the LEDs and the spectroradiometer at 9:54. The $V_{\mathrm{OC}}$ induced by the light transmitted through the leaf and SPFD of the leaf transmitted light were measured.

To confirm the reproducibility of phenomena observed on October 20, $V_{\mathrm{OC}} \mathrm{S}$ of the LEDs irradiated with sunlight were measured again on the same rooftop on 26 October 2020. The $V_{\mathrm{OC}} \mathrm{S}$ of the LEDs fixed toward the zenith at 9:00-17:30 were measured at $3 \mathrm{~s}$ intervals (34972A). The SPFD and PPFD of sunlight were measured at $60 \mathrm{~s}$ intervals using the spectroradiometer positioned proximate to the LEDs. The weather was fine. At 10:22, a lettuce leaf covered the LEDs and the spectroradiometer.

\section{Results and discussion}

\subsection{Open circuit voltage of LEDs irradiated by unimodal spectral light}

Table 1 presents $V_{\mathrm{OC}}$ induced in the $5 \mathrm{~mm}$ LEDs when they were irradiated with light emitted by one of the $3 \mathrm{~mm}$ LEDs of 17 types operating at their maximum rated forward current. The $V_{\mathrm{OC}} \mathrm{s}$ were induced when excitation light had a shorter wavelength than the inherent threshold wavelength of each $5 \mathrm{~mm}$ LED.

Figure 4 depicts SPFDs of the $3 \mathrm{~mm}$ LEDs and SPFDs that can be emitted by the receiver-side $5 \mathrm{~mm}$ LEDs. Figure 4a depicts the SPFDs of light emitted from the $3 \mathrm{~mm}$ LEDs respectively having $\lambda_{\mathrm{PE}}=387,408,445,494,525 \mathrm{~nm}$ that induced $V_{\mathrm{OC}} \mathrm{S}$ in $\mathrm{LED}_{464}$ and the SPFD emitted from $\lambda_{\mathrm{PE}}=594 \mathrm{~nm}$ LED that did not induce $V_{\mathrm{OC}}$ in $\mathrm{LED}_{464}$. The SPFDs emitted by the $3 \mathrm{~mm}$ LEDs with $\lambda_{\mathrm{PE}}=387$, $408,445 \mathrm{~nm}$ distributed completely on the shorter wavelength side of the $\mathrm{LED}_{464}$ spectrum. They induced $V_{\mathrm{OC}}$ of around $2.3 \mathrm{~V}$ in $\mathrm{LED}_{464}$ (Table 1). The spectral distributions of $\lambda_{\mathrm{PE}}=494,525 \mathrm{~nm}$ ranged in the longer wavelength side than the $\mathrm{LED}_{464}$ spectral peak. The shorter wavelength side of those spectra partially overlapped 
Table 1. Specifications of the emitter side 3-mm-diameter LEDs of 17 types and induced open circuit voltage $V_{\mathrm{OC}}$ values of the receiver side 5-mm-diameter LEDs of five types.

\begin{tabular}{|c|c|c|c|c|c|c|c|c|}
\hline \multicolumn{4}{|c|}{ Emitter LEDs } & \multicolumn{5}{|c|}{ Receiver LED open circuit voltage $V_{\mathrm{OC}}(\mathrm{V})$} \\
\hline$\lambda_{\mathrm{PE}}(\mathrm{nm})$ & $V_{\mathrm{F}}(\mathrm{V})$ & $I_{\mathrm{F}}(\mathrm{mA})$ & $\operatorname{PFD}\left(\mu \mathrm{mol} \mathrm{m} \mathrm{s}^{-2}\right)$ & $\mathrm{LED}_{464}$ & $\mathrm{LED}_{501}$ & $\mathrm{LED}_{634}$ & $\mathrm{LED}_{849}$ & $\mathrm{LED}_{455 / 574}$ \\
\hline 387 & 3.48 & 30 & 829 & 2.221 & 2.058 & 1.407 & 0.833 & 2.217 \\
\hline 408 & 3.58 & 40 & 1125 & 2.315 & 2.122 & 0.992 & 0.887 & 2.359 \\
\hline 445 & 3.40 & 30 & 1332 & 2.310 & 2.146 & 1.446 & 1.017 & 2.206 \\
\hline 494 & 3.50 & 30 & 814 & 1.552 & 1.907 & 1.553 & 1.020 & 0.082 \\
\hline 525 & 3.58 & 30 & 404 & 0.024 & 0.132 & 1.578 & 0.963 & 0.005 \\
\hline 594 & 2.05 & 40 & 203 & 0.000 & 0.000 & 1.586 & 0.860 & 0.000 \\
\hline 614 & 1.95 & 50 & 347 & 0.000 & 0.000 & 1.605 & 0.972 & 0.000 \\
\hline 644 & 2.04 & 40 & 216 & 0.000 & 0.000 & 1.539 & 0.870 & 0.000 \\
\hline 678 & 1.88 & 50 & 804 & 0.000 & 0.000 & 1.477 & 1.083 & 0.000 \\
\hline 700 & 2.03 & 50 & 984 & 0.000 & 0.000 & 0.641 & 1.094 & 0.000 \\
\hline 743 & 1.85 & 70 & 2414 & 0.000 & 0.000 & 0.002 & 1.111 & 0.000 \\
\hline 773 & 1.88 & 90 & 3772 & 0.000 & 0.000 & 0.001 & 1.133 & 0.000 \\
\hline 790 & 1.71 & 100 & 4664 & 0.000 & 0.000 & 0.000 & 1.149 & 0.000 \\
\hline 822 & 1.58 & 100 & 3598 & 0.000 & 0.000 & 0.000 & 1.138 & 0.000 \\
\hline 833 & 1.77 & 100 & 3959 & 0.000 & 0.000 & 0.000 & 1.135 & 0.000 \\
\hline 872 & 1.60 & 100 & 5565 & 0.000 & 0.000 & 0.000 & 1.068 & 0.000 \\
\hline 937 & 1.53 & 100 & 1720 & 0.000 & 0.000 & 0.000 & 0.016 & 0.000 \\
\hline
\end{tabular}

$\lambda_{\mathrm{PE}}$, emission peak wavelength; $V_{\mathrm{F}}$, forward voltage applied to the emitter side $3 \mathrm{~mm} \mathrm{LED}$; $I_{\mathrm{F}}$, forward current of the emitter LED; PFD, photon flux density

the $\mathrm{LED}_{464}$ spectrum. As the result, low $V_{\mathrm{OC}} \mathrm{s}$ were induced (Table 1). Because no overlap was found between the $\lambda_{\mathrm{PE}}=594 \mathrm{~nm}$ spectrum and the $\mathrm{LED}_{464}$ spectrum, $V_{\mathrm{OC}}=0 \mathrm{~V}$ (Table 1). A $V_{\mathrm{OC}}$ value induced by incident light corresponds to the intersection of the $I_{\mathrm{R}}$ curve and the $V_{\mathrm{F}}$ axis when the $I_{\mathrm{F}}$ curve is translated in the negative direction (Fig. 2). For this reason, the $V_{\mathrm{OC}}$ value can be greater than $2 \mathrm{~V}$ for $\mathrm{LED}_{464}, \mathrm{LED}_{501}$, and $\mathrm{LED}_{455 / 574}$, but it does not reach $2 \mathrm{~V}$ for $\mathrm{LED}_{634}$ and $\mathrm{LED}_{849}$. Similarly to $\mathrm{LED}_{464}, V_{\mathrm{OC}} \mathrm{S}$ were induced in $\mathrm{LED}_{501}$ by light irradiation with $\lambda_{\mathrm{PE}}=387,408$, $445,494,525 \mathrm{~nm}$, whereas $V_{\mathrm{OC}}=0 \mathrm{~V}$ by light irradiation with $\lambda_{\mathrm{PE}}=594 \mathrm{~nm}$ (Fig. 4b, Table 1). The spectra of $\lambda_{\mathrm{PE}}=743,773 \mathrm{~nm}$ ranged in the longer wavelength side than the $\mathrm{LED}_{634}$ spectrum (Fig. 4c). The shorter wavelength side of these spectra overlapped the $\mathrm{LED}_{634}$ spectrum slightly, inducing considerably low $V_{\mathrm{OC}} \mathrm{S}$. The emission spectra of the $3 \mathrm{~mm}$ LEDs of 17 types were of the shorter wavelength side or were overlapped with the $\mathrm{LED}_{849}$ spectrum. Therefore, they all induced $V_{\mathrm{OC}} \mathrm{S}$ (Fig. 4d, Table 1). Although the spectral distribution of $\lambda_{\mathrm{PE}}=594 \mathrm{~nm}$ overlapped with the secondary emission peak of the bimodal $\operatorname{LED}_{455 / 574}$ spectrum, it had longer wavelength than the wavelength range of the $\mathrm{LED}_{455 / 574}$ primary emission. For this reason, it did not induce $V_{\mathrm{OC}}$ for the $\mathrm{LED}_{455 / 574}$ (Fig. 4e, Table 1). The secondary peak was formed by emission from the package-embedded phosphors, which absorbed the primary emission. The phosphors are separated from the LED die. Therefore, light absorption by phosphors does not affect $V_{\mathrm{OC}}$, even if photons emitted from the $3 \mathrm{~mm}$ LED with $\lambda_{\mathrm{PE}}=594 \mathrm{~nm}$ are able to interact with the phosphors. Possible emissions from the phosphors by absorbing the $\lambda_{\mathrm{PE}}=594 \mathrm{~nm}$ light can be expected to have longer wavelengths than $594 \mathrm{~nm}$, which is not sensible in terms of the photovoltaic effect for the $\mathrm{LED}_{455 / 574}$ die.

In this way, when a photon having wavelength shorter than or overlapping with the unimodal $5 \mathrm{~mm}$ LED emission spectrum impinges the $5 \mathrm{~mm}$ LED, the photon energy exceeding the semiconductor bandgap is transferred to a hole-electron pair (Cuevas et al., 2000). Consequently, $V_{\mathrm{OC}}$ is induced in the $5 \mathrm{~mm}$
LED. $V_{\mathrm{OC}}$ is not induced if the impinged photon energy is less than the bandgap. This phenomenon is consistent with data reported by Vannacci et al. (2019) who presented data of overlapping emission and absorption spectra of an LED. Their spectral data clearly demonstrated the same cut-off at the spectral longest wavelengths, whereas a broader distribution of the absorption spectrum extended to the shorter wavelength side by the Stokes shift (Martin et al., 1999; Yang et al., 1993). Accordingly, the longest wavelength limit of each emission spectrum of the four unimodal LEDs is defined as the voltage-inducible threshold wavelength $\lambda_{\text {th }}$ (Table 2). For $\operatorname{LED}_{455 / 574}$, which has a bimodal emission spectrum, the spectral shape forming the $455 \mathrm{~nm}$ primary-peak is assumed to be approximately symmetrical. Then, the wavelength interval from $\lambda_{\mathrm{PR}}=455 \mathrm{~nm}$ to the shortest-wavelength emission limit is assumed to be as long as the interval from the $\lambda_{\mathrm{PR}}$ to the longest-wavelength emission limit of the primary-peak. The $\lambda_{\text {th }}$ of $\mathrm{LED}_{455 / 574}$ was defined as the longest-wavelength limit of the assumed primary-emission spectrum.

Photons emitted from the $3 \mathrm{~mm}$ LEDs having $\lambda_{\mathrm{PE}}=408,445$, 614,790 , and $408 \mathrm{~nm}$ respectively induced the maximum $V_{\mathrm{OC}} \mathrm{S}$ in $\mathrm{LED}_{464}, \mathrm{LED}_{501}, \mathrm{LED}_{634}, \mathrm{LED}_{849}$, and $\mathrm{LED}_{455 / 574}$ (Table 1). Each pair of the $3 \mathrm{~mm}$ LEDs and the $5 \mathrm{~mm}$ LEDs [i.e. (408 $\mathrm{nm} \lambda_{\mathrm{PE}}$, $\left.\mathrm{LED}_{464}\right),\left(445 \mathrm{~nm} \lambda_{\mathrm{PE}}, \mathrm{LED}_{501}\right),\left(614 \mathrm{~nm} \lambda_{\mathrm{PE}}, \mathrm{LED}_{634}\right),\left(790 \mathrm{~nm} \lambda_{\mathrm{PE}}\right.$, $\left.\mathrm{LED}_{849}\right)$, and (408 $\left.\left.\mathrm{nm} \lambda_{\mathrm{PE}}, \mathrm{LED}_{455 / 574}\right)\right]$ was faced to the other so that the $3 \mathrm{~mm}$ LED acts as the light emitter and the $5 \mathrm{~mm}$ LED as the receiver (Fig. 3). The radiated photon flux density was changed by regulating the power applied to the $3 \mathrm{~mm}$ LEDs. The relation between the effective photon flux density $\left(E_{\text {eff }}\right)$ having shorter wavelengths than $\lambda_{\text {th }}$ and the induced $V_{\mathrm{OC}}$ was found experimentally (Fig. 5). Values of photon flux density emitted from each $3 \mathrm{~mm}$ LED were measured using the spectroradiometer positioned near each LED. When the $E_{\text {eff }}$ axis was plotted logarithmically, three distinct regions, designated as Zones I, II, and III, were found respectively as representing the $V_{\mathrm{OC}}$ conditions of being zero, of sharp inclination, and of saturation. Because $V_{\mathrm{OC}} \mathrm{S}$ 

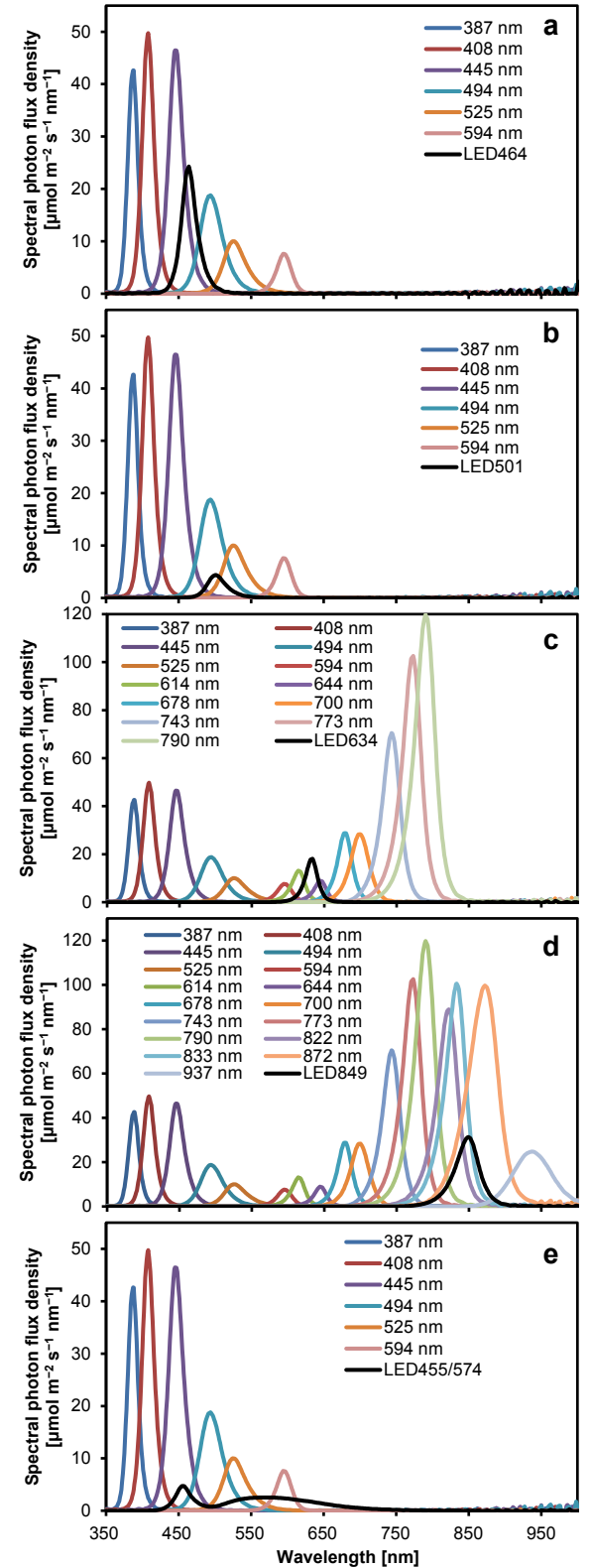

Fig. 4. Spectral photon flux densities of 3-mm-diameter emitter LEDs (represented by each $\lambda_{\mathrm{PE}}$ values) and of $5 \mathrm{~mm}$ receiver LEDs (black solid lines).

(a) $\mathrm{LED}_{464}$ and $V_{\mathrm{OC}}$ inducible emitter side LEDs excepting $\lambda_{\mathrm{PE}}=594 \mathrm{~nm} \mathrm{LED}$; (b) $\mathrm{LED}_{501}$ and $V_{\mathrm{OC}}$ inducible emitter side LEDs excepting $\lambda_{\mathrm{PE}}=594 \mathrm{~nm} \mathrm{LED;} \mathrm{(c)} \mathrm{LED}_{634}$ and $V_{\mathrm{OC}}$ inducible emitter side LEDs excepting $\lambda_{\mathrm{PE}}=790 \mathrm{~nm}$ LED; (d) LED L $_{849}$ and $V_{\mathrm{OC}}$ inducible emitter side LEDs; (e) $\mathrm{LED}_{455 / 574}$ and $V_{\mathrm{OC}}$ inducible emitter side LEDs excepting $\lambda_{\mathrm{PE}}=594 \mathrm{~nm}$ LED

of the three zones cannot be approximated by a single equation, coefficients $a$ and $b$ that approximate the relation between $V_{\mathrm{OC}}$ and $E_{\text {eff }}$ were found respectively in each zone by equation 5 (Table 2). The $V_{\mathrm{OC}} \mathrm{s}$ curves were also plotted on a proportional scale $E_{\text {eff }}$ axes (Fig. $5 \mathrm{f}-\mathrm{j}$ ). The measured $V_{\mathrm{OC}}$ values can be approximated by equation 5 .

\subsection{Open circuit voltage of LEDs irradiated with sunlight}

Figure 6 depicts sunlight PPFD and $V_{\mathrm{OC}}$ measured on 20 October 2020. Scud cumulus clouds occasionally covered the sun at around 11 o'clock. At 9:54, the lettuce leaf covered the LEDs and the spectroradiometer, causing the PPFD and $V_{\mathrm{OC}}$ values to drop sharply and temporarily. The progress of $V_{\mathrm{OC}} \mathrm{S}$ was classified into three types: saturated, follow-up, and invariant in response to the PPFD increase over time (Fig. 6a). The $V_{\mathrm{OC}} \mathrm{S}$ of $\mathrm{LED}_{464}, \mathrm{LED}_{501}$, and $\mathrm{LED}_{849}$ were saturated, respectively, at $1.9 \mathrm{~V}, 1.9 \mathrm{~V}$, and $1.0 \mathrm{~V}$ when the PPFD values were greater than $1100 \mu \mathrm{mol} \mathrm{m}{ }^{-2} \mathrm{~s}^{-1}$. These $V_{\mathrm{OC}}$ values were slightly less than the respective saturation voltage values (Fig. 5) obtained by the unimodal light irradiation. The $V_{\mathrm{OC}}$ of $\mathrm{LED}_{455 / 574}$ followed the PPFD fluctuation to some degree without saturation. The $V_{\mathrm{OC}}$ of $\mathrm{LED}_{634}$ remained at a constant value of $1.5 \mathrm{~V}$ without being affected by the leaf and cloud cover.

Figure 7 depicts sunlight PPFD, and $V_{\mathrm{OC}}$ measured on 26 October 2020. The maximum value of the PPFD was $1345 \mu \mathrm{mol} \mathrm{m} \mathrm{s}^{-1}$ at $11: 43: 00$. Although it was a sunny day with no visible clouds, $V_{\mathrm{OC}}$ and PPFD dropped sharply when the LEDs were covered with the lettuce leaf in the morning and when the sun positioned westerly in the late afternoon, during which time direct sunlight was hidden temporarily behind some university buildings and structures. The $V_{\mathrm{OC}} \mathrm{S}$ of $\mathrm{LED}_{464}$ and $\mathrm{LED}_{849}$ were saturated respectively at $1.9 \mathrm{~V}$ and $1.0 \mathrm{~V}$, when the PPFD values were greater than $1100 \mu \mathrm{mol} \mathrm{m}^{-2} \mathrm{~s}^{-1}$. These saturation voltages resemble those obtained during the October 20 experiment. The $V_{\mathrm{OC}} \mathrm{S}$ of $\mathrm{LED}_{501}$ and $\mathrm{LED}_{455 / 574}$ followed the progress of PPFD to some extent without saturation. The $\mathrm{LED}_{634}$ $V_{\text {OC }}$ saturated at $1.5 \mathrm{~V}$ until PPFD decreased to $52 \mu \mathrm{mol} \mathrm{m} \mathrm{m}^{-2}$ at 16:50 (Fig. 7a). The $V_{\mathrm{OC}}$ dropped sharply at sunset. Results show that the $\mathrm{LED}_{634} V_{\mathrm{OC}}$ can be used for binary discrimination between daytime and nighttime for outdoor cultivation.

Fig. 8 depicts the relation between incident $E_{\text {eff }}$ and induced $V_{\mathrm{OC}}$ of the LEDs of five types when incident sunlight irradiated the LEDs without any disturbance on 26 October 2020. The relation between $E_{\text {eff }}$ and $V_{\mathrm{OC}}$ varied depending on the LED type. The $V_{\mathrm{OC}}-E_{\text {eff }}$ relational functions obtained using equation 5 were drawn in Fig. 8. Coefficients $a$ and $b$ are presented in Table 2. Because the $\mathrm{LED}_{634} V_{\mathrm{OC}}$ was saturated at $E_{\text {eff }}=40 \mu \mathrm{mol} \mathrm{m} \mathrm{m}^{-2}$ or greater and the function property changed (Fig. 8c), $a$ and $b$ were found separately for Zones II and III, as in the case of the unimodal light experiments. The deviation between equation 5 and the measured values increased when sunlight became the light source. One possible cause of the deviation is the wavelength dependence of the photovoltaic effects (Filippo et al., 2017; Haydaroglu and Mutlu, 2015; Vannacci et al., 2018; Vannacci et al., 2019). Table 1 shows that $\mathrm{LED}_{849}$ induced $0.870 \mathrm{~V}$ of $V_{\mathrm{OC}}$ with a photon flux density of only $216 \mu \mathrm{mol} \mathrm{m} \mathrm{m}^{-2} \mathrm{~s}^{-1}$ by unimodal light irradiation with $\lambda_{\mathrm{PE}}=644 \mathrm{~nm}$. By unimodal light with $\lambda_{\mathrm{PE}}=387 \mathrm{~nm}, \mathrm{LED}_{849}$ induced merely $0.833 \mathrm{~V}$, even though the incident photon flux density was $829 \mu \mathrm{mol} \mathrm{m} \mathrm{m}^{-2}$. Therefore, the sensitivity of $V_{\mathrm{OC}}$ depends on the incident light spectrum. The $V_{\mathrm{OC}} \mathrm{s}$ were induced by photons having wavelengths shorter than $\lambda_{\text {th }}$. Even for lights having the same $E_{\text {eff }}$ value, the wavelength ranges of included photons differ greatly between unimodal light and sunlight. In the sunlight spectrum with wavelengths shorter than $\lambda_{\mathrm{th}}$, photons having $V_{\mathrm{OC}}$ sensitive wavelengths and photons having wavelengths that are less $V_{\mathrm{OC}}$ sensitive coexist. When the proportion of the less-sensitive photons becomes dominant in sunlight $E_{\text {eff, }}$ the sunlight induces a lower $V_{\mathrm{OC}}$ value than the $V_{\mathrm{OC}}$ sensitive unimodal light having the same $E_{\text {eff }}$ value as that of the sunlight. 


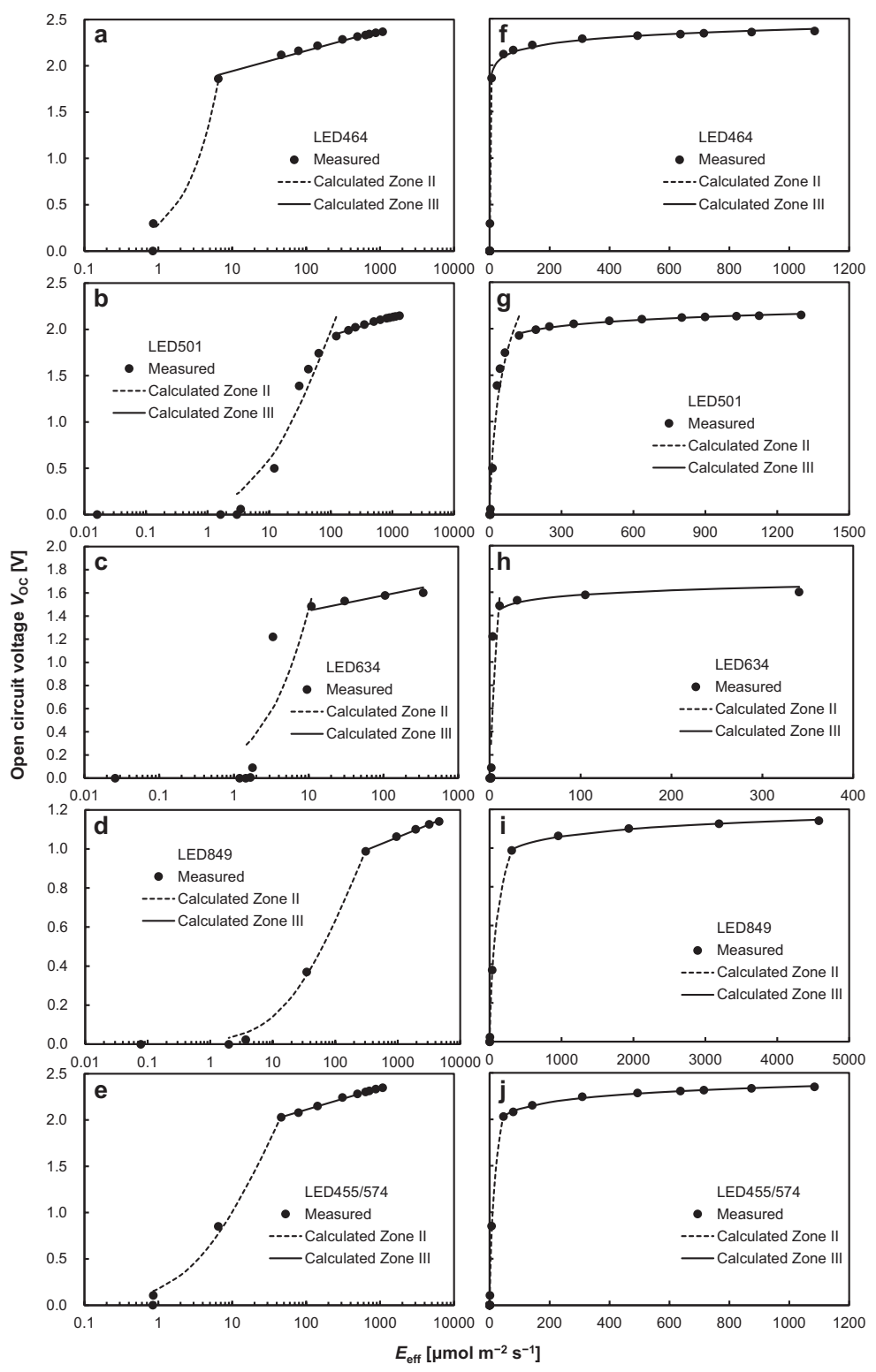

Fig. 5. Logarithmic $(\mathrm{a}-\mathrm{e})$ and linear $(\mathrm{f}-\mathrm{j})$ plots of the relation between the $E_{\text {eff }}$ of unimodal spectral light incident on the 5-mm-diameter receiver LEDs and the induced open circuit voltage $V_{\mathrm{OC}}$.

Curves are fitted using equation 5 with respective coefficients $a$ and $b$ reported in Table 2. $\operatorname{LED}_{464}(\mathrm{a}, \mathrm{f}), \mathrm{LED}_{501}(\mathrm{~b}, \mathrm{~g})$, $\operatorname{LED}_{634}(\mathrm{c}, \mathrm{h}), \operatorname{LED}_{849}(\mathrm{~d}, \mathrm{i})$, and $\operatorname{LED}_{455 / 574}(\mathrm{e}, \mathrm{j})$ were irradiated by $3 \mathrm{~mm}$ LED emissions with respective $\lambda_{\mathrm{PE}}=408 \mathrm{~nm}$, $445 \mathrm{~nm}, 614 \mathrm{~nm}, 790 \mathrm{~nm}$, and $408 \mathrm{~nm}$.

\subsection{Open circuit voltage of LEDs irradiated with light transmitted through plant leaves}

Covering the LEDs and the spectroradiometer with a single lettuce leaf decreased PPFD from $1196 \mu \mathrm{mol} \mathrm{m}^{-2} \mathrm{~s}^{-1}$ at 9:53:30 to $302 \mu \mathrm{mol} \mathrm{m} \mathrm{s}^{-2}$ at 9:54:00 on October 20 (Fig. 6b). Figure 9a depicts the incident light spectra on the LEDs at 9:53:30 and at $9: 54: 00$. By means of photon absorption by chlorophylls, SPFD decreased sharply at less than $500 \mathrm{~nm}$ and around 680 $\mathrm{nm}$. As a result, $V_{\mathrm{OC}} \mathrm{S}$ of $\mathrm{LED}_{464}, \mathrm{LED}_{501}$ and $\mathrm{LED}_{455 / 574}$ having short $\lambda_{\mathrm{th}} \mathrm{S}$ were decreased substantially (Figs. $6 \mathrm{~b}$ and 10a). In contrast, $73 \%$ of the sunlight SPFD was available in the lettuce leaf shadow in the wavelength band of 700-900 nm (Fig. 9a). The transmitted light spectrum was concentrated at 700-900 $\mathrm{nm}$ by the lettuce leaf covering. For this reason, the relation between $V_{\mathrm{OC}}$ and $E_{\text {eff }}$ of $\mathrm{LED}_{849}$ was closer to that obtained by the unimodal light irradiation with $\lambda_{\mathrm{PE}}=790 \mathrm{~nm}$ (Fig. 5i) than that obtained by sunlight irradiation (Fig. 8d). Behind the lettuce leaf, $927 \mu \mathrm{mol} \mathrm{m} \mathrm{m}^{-2} \mathrm{~s}^{-1}$ of $E_{\text {eff }}$ (Table 3) irradiated $\mathrm{LED}_{849}$. The $E_{\text {eff }}$ value was sufficient to saturate $V_{\mathrm{OC}}$ (Fig. 5i). Therefore, the $\mathrm{LED}_{849} V_{\mathrm{OC}}$ was unaffected by the lettuce leaf shadow (Fig. 6b, Fig. 10a). Even in the lettuce leaf shadow, LED $_{634}$ was irradiated with $E_{\text {eff }}=295 \mu \mathrm{mol} \mathrm{m} \mathrm{m}^{-2} \mathrm{~s}^{-1}$ (Table 3), which was sufficient to saturate $V_{\mathrm{OC}}$ (Fig. 8c). Accordingly, the $V_{\mathrm{OC}}$ value of $\mathrm{LED}_{634}$ was unaffected by the lettuce leaf shadow (Fig. 6b, Fig. 10a). At $11: 31: 00$, PPFD decreased to $446 \mu \mathrm{mol} \mathrm{m}^{-2} \mathrm{~s}^{-1}$ because the sunlight was shaded by clouds (Fig. 6c). The spectral change at this event is presented in Fig. 9c. In the shadow of clouds, the proportion of longer wavelength components decreased to a relative degree. Consequently, $\mathrm{LED}_{849} V_{\mathrm{OC}}$ was decreased (Fig. 6c, Fig. 10d), whereas no $V_{\mathrm{OC}}$ decrease was observed in $\mathrm{LED}_{849}$ 
Table 2. Threshold wavelength $\lambda_{\text {th }}$ of $V_{\mathrm{OC}}$ inducible photons and estimated coefficients $a$ and $b$ for fitting experimentally

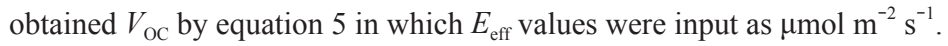

\begin{tabular}{|c|c|c|c|c|c|c|c|}
\hline & & & \multicolumn{5}{|l|}{ Receiver LED } \\
\hline & & & $\mathrm{LED}_{464}$ & $\mathrm{LED}_{501}$ & $\mathrm{LED}_{634}$ & $\mathrm{LED}_{849}$ & $\mathrm{LED}_{455 / 574}$ \\
\hline \multicolumn{3}{|l|}{$\lambda_{\mathrm{th}}[\mathrm{nm}]$} & 561 & 590 & 692 & 921 & 506 \\
\hline \multirow{6}{*}{$\begin{array}{l}\text { Unimodal } \\
\text { spectral } \\
\text { light }\end{array}$} & \multirow[t]{2}{*}{ Zone I } & $a$ & - & - & - & - & - \\
\hline & & $b$ & 0 & 0 & 0 & 0 & 0 \\
\hline & \multirow[t]{2}{*}{ Zone II } & $a$ & 47.437 & 0.80763 & 2.0839 & 0.36080 & 0.81813 \\
\hline & & $b$ & $6.0828 \times 10^{-3}$ & 0.10618 & 0.10148 & $4.7529 \times 10^{-2}$ & 0.24247 \\
\hline & \multirow[t]{2}{*}{ Zone III } & $a$ & $9.5461 \times 10^{-2}$ & $8.9545 \times 10^{-2}$ & $5.6630 \times 10^{-2}$ & $5.6841 \times 10^{-2}$ & 0.10335 \\
\hline & & $b$ & $68563 \times 10^{2}$ & $22924 \times 10^{2}$ & $12605 \times 10^{6}$ & 125030 & $74543 \times 10^{2}$ \\
\hline \multirow[t]{4}{*}{ Sunlight } & \multirow[t]{2}{*}{ Zone II } & $a$ & 1.6284 & 2.0743 & 1.8321 & 0.30470 & 0.55264 \\
\hline & & $b$ & $3.1406 \times 10^{-3}$ & $1.6834 \times 10^{-3}$ & $2.6813 \times 10^{-2}$ & $8.5194 \times 10^{-3}$ & $1.0274 \times 10^{-2}$ \\
\hline & \multirow{2}{*}{ Zone III } & $a$ & - & - & $7.3592 \times 10^{-2}$ & - & - \\
\hline & & $b$ & - & - & $17392 \times 10^{2}$ & - & - \\
\hline
\end{tabular}

Zones I, II, and III respectively represent ranges with no $V_{\mathrm{OC}}$ induction, steep $V_{\mathrm{OC}}$ increment, and $V_{\mathrm{OC}}$ saturation.
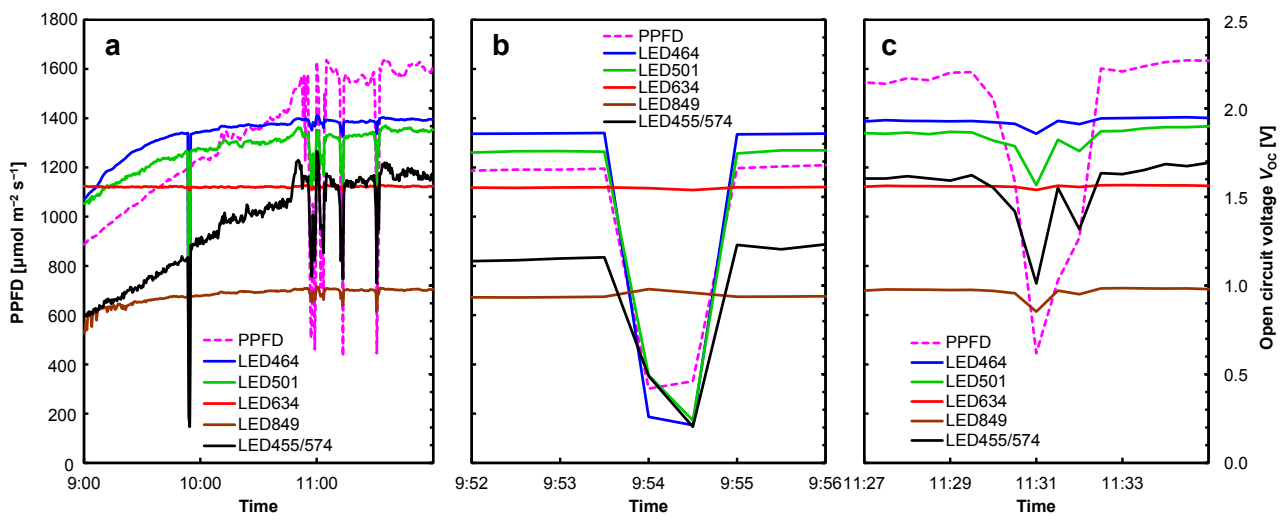

Fig. 6. Transitions of PPFD and LED open circuit voltage $V_{\text {OC }}$ measured outdoors on 20 October 2020 (a), effects of shading by a single lettuce leaf (b), and effects of shading by scud cumulus clouds (c).

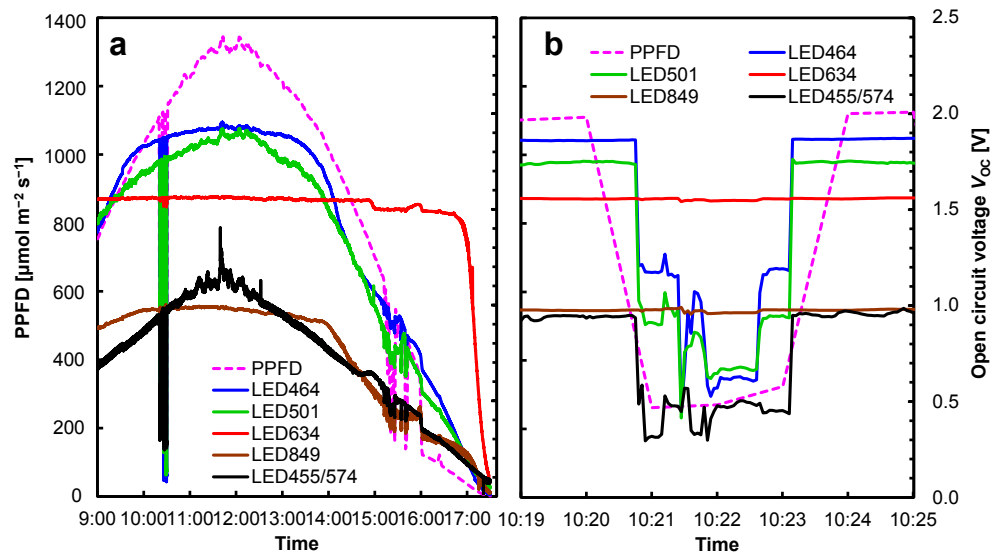

Fig. 7. Transitions of PPFD and LED open circuit voltage $V_{\text {OC }}$ on 26 October 2020 (a) and effects of shading by a single lettuce leaf (b). The instantaneous shading data (b) were unstable because the leaf swaying in the wind was held by hands.

under the leaf shadow.

Covering the LEDs and the spectroradiometer with a single lettuce leaf at 10:22:00 on October 26 led to PPFD of $270 \mu \mathrm{mol} \mathrm{m}^{-2} \mathrm{~s}^{-1}$ (Fig. 7b). Immediately before that moment, the PPFD on the LEDs at 10:20:00 was $1110 \mu \mathrm{mol} \mathrm{m}^{-2} \mathrm{~s}^{-1}$. Figure $9 \mathrm{~b}$ depicts incident light spectra on the LEDs at 10:20:00 and at 10:22:00. Similarly to October 20 data, $73 \%$ of sunlight SPFD was obtained behind the lettuce leaf in the wavelength band of 700-900 nm. The $V_{\mathrm{OC}} \mathrm{S}$ of $\mathrm{LED}_{455 / 574}, \mathrm{LED}_{464}$ and
$\mathrm{LED}_{501}$ decreased because the photon flux density in the shorter wavelength range decreased considerably, whereas the $V_{\mathrm{OC}} \mathrm{S}$ of $\mathrm{LED}_{634}$ and $\mathrm{LED}_{849}$ were unaffected by attenuation of the photon flux density in the lettuce leaf shadow (Figs. $7 \mathrm{~b}$ and 10b).

At 16:00:00 on October 26, PPFD attenuated to $235 \mu \mathrm{mol} \mathrm{m} \mathrm{m}^{-2} \mathrm{~s}^{-1}$ (Fig. 9d) by the sunlight natural decrement. This value was closest to $270 \mu \mathrm{mol} \mathrm{m}^{-2} \mathrm{~s}^{-1}$ obtained by covering the LEDs with the lettuce leaf. The sky had no clouds at 16:00. Because $E_{\text {eff }}=243 \mu \mathrm{mol} \mathrm{m} \mathrm{m}^{-2} \mathrm{~s}^{-1}$ was obtained (Table 3), the 

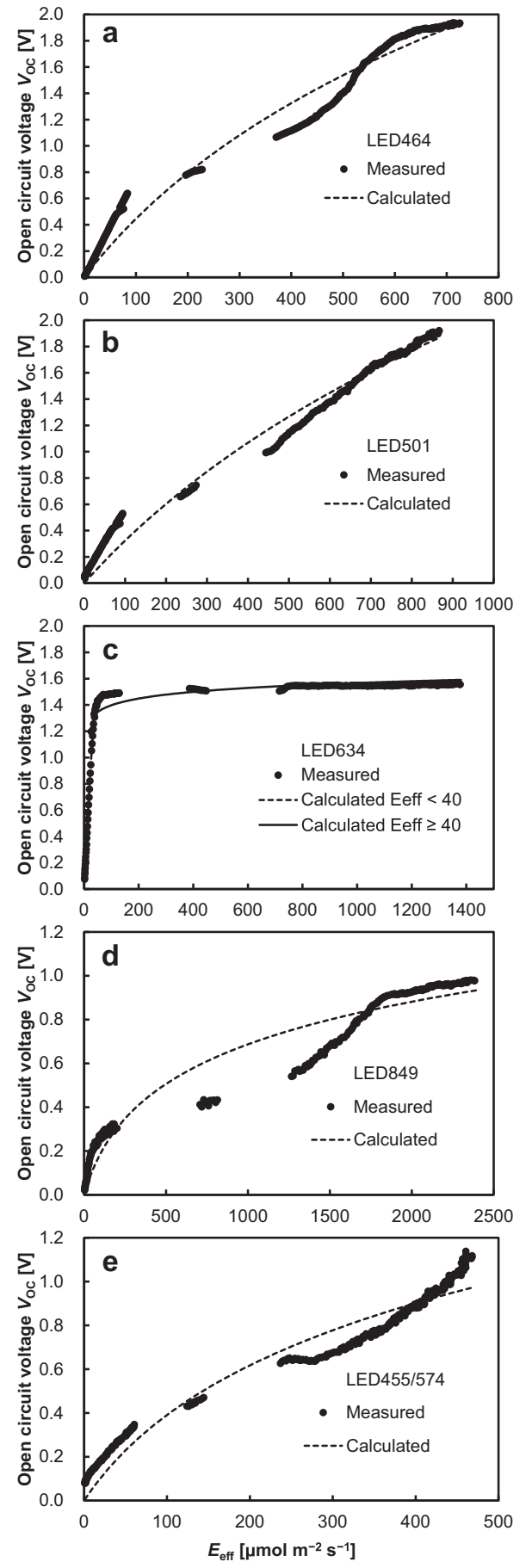

Fig. 8. Relation between $E_{\text {eff }}$ of sunlight incident and the open circuit voltage $V_{\mathrm{OC}}$.

Curves were fitted respectively using equation 5 with coefficients $a$ and $b$ reported in Table 2 .
(a) $\operatorname{LED}_{464}$, (b) $\mathrm{LED}_{501}$, (c) $\mathrm{LED}_{634}$, (d) $\mathrm{LED}_{849}$, and (e) $\mathrm{LED}_{455 / 574}$

$\mathrm{LED}_{634} V_{\mathrm{OC}}$ retained saturation (Fig. 8c). The $V_{\mathrm{OC}}$ saturation value (Fig. 10c) was almost the same as the $V_{\text {OC }}$ obtained at 10:22 in the lettuce leaf shadow (Fig. 10b). Therefore, it is not possible to distinguish from the $V_{\mathrm{OC}}$ values of $\mathrm{LED}_{634}$ whether the PPFD attenuation is attributable to the solar irradiance decrease or shading by leaves. In contrast, a clear attenuation in the $\mathrm{LED}_{849}$ $V_{\mathrm{OC}}$ value was obtained when PPFD decreased to $235 \mu \mathrm{mol} \mathrm{m}^{-2} \mathrm{~s}^{-1}$ at $16: 00$ by the sunlight natural decrement (Fig. 10c), compared

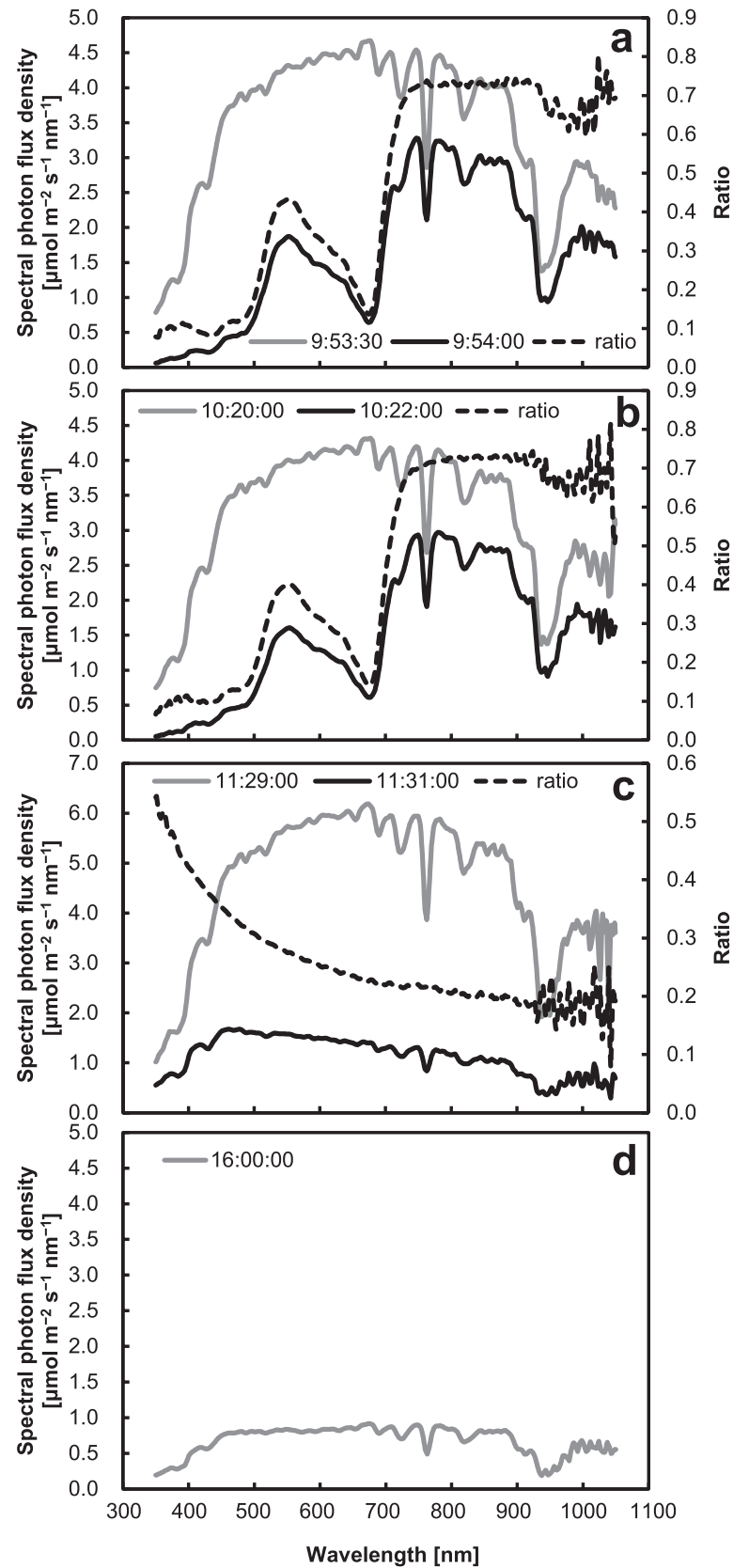

Fig. 9. Spectral photon flux density (SPFD) of sunlight incident on the LEDs.

(a) SPFD of incident light on the LEDs at 9:53:30 just before covering the LEDs with the lettuce leaf on 20 October 2020, SPFD at 9:54:00 during the covering, and their ratio; (b) SPFD of incident light on the LEDs at 10:20:00 just before covering the LEDs with the lettuce leaf on 26 October 2020, SPFD at 10:22:00 during the covering, and their ratio; (c) SPFD of incident light on the LEDs at 11:29:00 just before the sun was obscured by scud clouds on 20 October 2020, SPFD at 11:31:00 when the sun was obscured by the scud cumulus clouds, and their ratio; (d) SPFD at 16:00:00 on 26 October 2020

to the other $\mathrm{LED}_{849} V_{\mathrm{OC}}$ value obtained when PPFD was reduced to $270 \mu \mathrm{mol} \mathrm{m} \mathrm{m}^{-2} \mathrm{~s}^{-1}$ as the result of lettuce leaf shadow (Fig. 10b). Under natural sunlight conditions, the magnitude relation of $V_{\mathrm{OC}} \mathrm{S}$ was $\mathrm{LED}_{464}, \mathrm{LED}_{501}>\mathrm{LED}_{849}$ irrespective of the sunlight intensity (white bars in Fig. 10). However, the $V_{\mathrm{OC}}$ magnitude 
Table 3. Leaf shading effects on photon flux density $E_{\text {eff }}$ impinged LEDs.

\begin{tabular}{|c|c|c|c|c|c|c|c|}
\hline & & & $E_{\text {eff }}[\mu \mathrm{mol}$ & & & & \\
\hline & & & $\mathrm{LED}_{464}$ & $\mathrm{LED}_{501}$ & $\mathrm{LED}_{634}$ & $\mathrm{LED}_{849}$ & $\mathrm{LED}_{455 / 574}$ \\
\hline 20 October & Sunlight & $9: 53: 30$ & 641 & 767 & 1224 & 2128 & 412 \\
\hline & Lettuce & $9: 54: 00$ & 134 & 182 & 295 & 927 & 48 \\
\hline & Sunlight & $11: 29: 00$ & 846 & 1014 & 1621 & 2820 & 543 \\
\hline & Cloudy & $11: 31: 00$ & 285 & 329 & 474 & 722 & 199 \\
\hline 26 October & Sunlight & $10: 20: 00$ & 597 & 713 & 1137 & 1981 & 384 \\
\hline & Lettuce & $10: 22: 00$ & 122 & 163 & 265 & 843 & 47 \\
\hline & Afternoon sunlight & $16: 00: 00$ & 133 & 157 & 243 & 418 & 89 \\
\hline
\end{tabular}

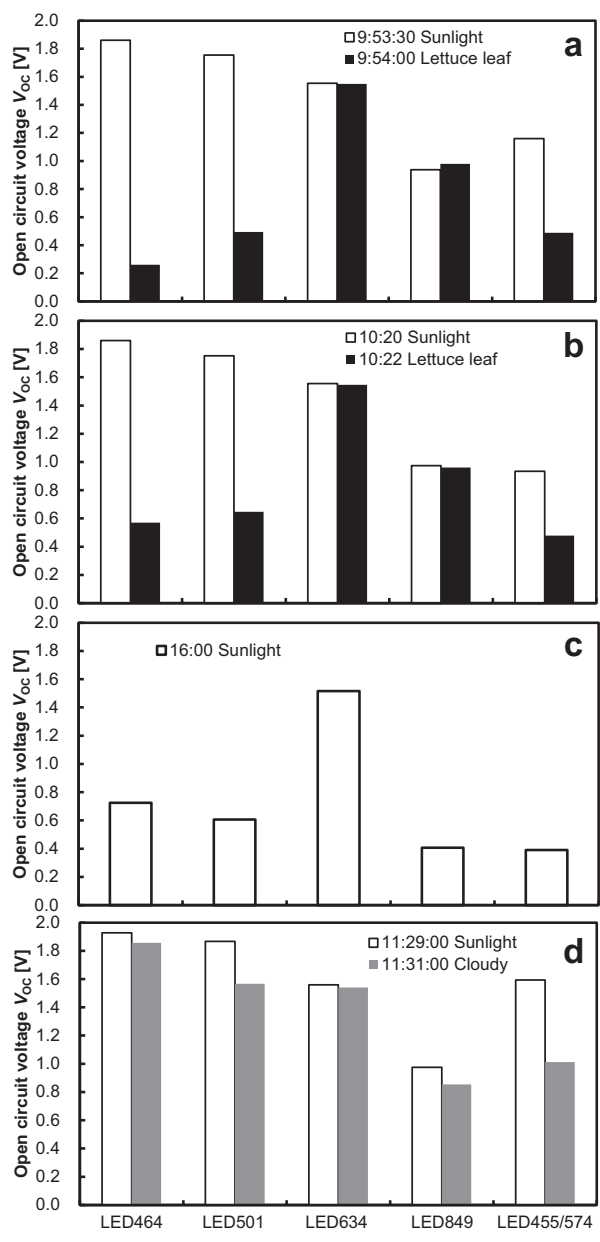

Fig. 10. Effects of shading by lettuce leaves on $V_{\mathrm{OC}}$ (October 20 a; October 26 b), $V_{\text {OC }}$ at 16:00 on October 26 when PPFD was $235 \mu \mathrm{mol} \mathrm{m} \mathrm{m}^{-2} \mathrm{~s}^{-1}$, which was the closest measured value to the PPFD at 10:22 under the lettuce leaf shadow (c), and $V_{\mathrm{OC}}$ at the moment when sunlight was covered by scud cumulus clouds on October 20 (d).

relation was $\mathrm{LED}_{849}>\mathrm{LED}_{464}, \mathrm{LED}_{501}$ in the shadow of lettuce leaves. Accordingly, the magnitude comparison between the $\mathrm{LED}_{849} V_{\mathrm{OC}}$ and the $V_{\mathrm{OC}}$ of $\mathrm{LED}_{464}$ and $\mathrm{LED}_{501}$ can discriminate the difference between light attenuation causes, one of which is attributable to natural sunlight attenuation by changes in solar altitude and cloud covering, and the other one of which is attributable to shading by plant leaves.

\section{Conclusions}

We investigated the light environment information obtained from the open circuit voltages of the turned-off LEDs. Few studies have reported the potential use of this information in plant cultivation practices. This study clarified that the open circuit voltage reflects the photon flux density around plants. Furthermore, results suggest that LED open circuit voltages can be used to extract characteristics and variations of qualitative light distribution in a cultivation space by taking advantage of numerous LED installations near the plants. An LED with open circuit voltage that saturates at a low photon flux density can be used for binary discrimination between daylight and night. A threshold wavelength of light exists for inducement of the open circuit voltage to an LED. By virtue of this feature, existence of plant leaves between a light source and the LEDs can be detected by comparing the open circuit voltage relations between blue-green range LEDs and NIR LEDs.

\section{Acknowledgments}

This work was supported by JSPS KAKENHI Grant-in-Aid for Scientific Research (A) [grant number JP18H03966].

\section{References}

Acharya YB, Jayaraman A, Ramachandran S et al., 1995: Compact light-emitting-diode sun photometer for atmospheric optical depth measurements. Applied Optics 34, 1209-1214. https://doi.org/10.1364/AO.34.001209

Akasaki I, Amano H, Murakami H et al., 1993: Growth of $\mathrm{GaN}$ and $\mathrm{AlGaN}$ for UV/blue p-n junction diodes. Journal of Crystal Growth 128, 379-383. https://doi.org/10.1016/0022-0248(93)90352-W

Benke K, Tomkins B, 2017: Future food-production systems: vertical farming and controlled-environment agriculture. Sustainability: Science Practice and Policy 13, 13-26. https://doi.org/10.1080/15487733.2017.1394054

Bula RJ, Morrow RC, Tibbitts TW et al., 1991: Light-emitting diodes as a radiation source for plants. HortScience 26, 203-205. https://doi.org/10.21273/HORTSCI.26.2.203

Cochard P, Galstian T, Cloutier C, 2019: The proportion of blue light affects parasitoid wasp behavior in LED extended photoperiod in greenhouses: Increased parasitism and offspring sex ratio bias. Biological Control 133, 9-17. https://doi.org/10.1016/j.biocontrol.2019.03.004

Cope KR, Bugbee B, 2013: Spectral effects of three types of white light-emitting diodes on plant growth and development: absolute versus relative amounts of blue light. HortScience 48, 504-509. https://doi.org/10.21273/HORTSCI.48.4.504

Cuevas A, Hill R, Markvart T, 2000: Solar cells. In Solar Electricity ed. by Markvart T, John Wiley \& Sons, Chichester, pp. 23-74.

Deram P, Lefsrud MG, Orsat V, 2014: Supplemental lighting orientation and red-to-blue ratio of light-emitting diodes for 
greenhouse tomato production. HortScience 49, 448-452. https://doi.org/10.21273/HORTSCI.49.4.448

Filippo R, Taralli E, Rajteri M, 2017: LEDs: sources and intrinsically bandwidth-limited detectors. Sensors 17, 1673. https://doi.org/10.3390/s17071673

Haydaroglu I, Mutlu S, 2015: Optical power delivery and data transmission in a wireless and batteryless microsystem using a single light emitting diode. Journal of Microelectromechanical Systems 24, 155-165. 10.1109/JMEMS.2014.2323202

Hernándes R, Kubota C, 2016: Physiological responses of cucumber seedlings under different blue and red photon flux ratios using LEDs. Environmental and Experimental Botany 121, 66-74. https://doi.org/10.1016/j.envexpbot.2015.04.001

Hikosaka S, Iyoki S, Hayakumo M et al., 2013: Effects of light intensity and amount of supplemental LED lighting on photosynthesis and fruit growth of tomato plants under artificial conditions. Journal of Agricultural Meteorology 69, 93-100.

Huché-Thélier L, Crespel L, Gourrierec JL et al., 2016: Light signaling and plant responses to blue and UV radiations-Perspectives for applications in horticulture. Environmental and Experimental Botany 121, 22-38. https://doi.org/10.1016/j.envexpbot.2015.06.009

Ibaraki Y, Shigemoto C, 2013: Estimation of supplemental lighting efficiency based on PPFD distribution on the canopy surface. Journal of Agricultural Meteorology 69, 47-54.

Jeong SW, Hogewoning SW, van Ieperen W, 2014: Responses of supplemental blue light on flowering and stem extension growth of cut chrysanthemum. Scientia Horticulturae 165, 69-74. http://dx.doi.org/10.1016/j.scienta.2013.11.006

Joshi NC, Ratner K, Eidelman O et al., 2019: Effects of daytime intra-canopy LED illumination on photosynthesis and productivity of bell pepper grown in protected cultivation. Scientia Horticulturae 250, 81-88. https://doi.org/10.1016/j.scienta.2019.02.039

Kim J, Ryu Y, Jiang C et al., 2019: Continuous observation of vegetation canopy dynamics using an integrated low-cost, near-surface remote sensing system. Agricultural and Forest Meteorology 264, 164-177. https://doi.org/10.1016/j.agrformet.2018.09.014

Kitazaki K, Fukushima A, Nakabayashi R et al., 2018: Metabolic reprogramming in leaf lettuce grown under different light quality and intensity conditions using narrow-band LEDs. Scientific Reports 8, 7914.

Kliss M, MacElroy RD, 1990: Salad machine: a vegetable production unit for long duration space missions. SAE Transactions 99, 722-729. http://www.jstor.org/stable/44472534

Kopsell DA, Sams CE, Barickman TC et al., 2014: Sprouting broccoli accumulate higher concentrations of nutritionally important metabolites under narrow-band light-emitting diode lighting. Journal of the American Society for Horticultural Science 139, 469-477. https://doi.org/10.21273/JASHS.139.4.469

Kozai T, 2013: Resource use efficiency of closed plant production system with artificial light: Concept, estimation and application to plant factory. Proceedings of the Japan Academy Series B 89, 447-461. https://doi.org/10.2183/pjab.89.447

Kozai T, Niu G, Takagaki M (eds.), 2020: Plant factory (2nd ed.). Academic Press, London, pp. 1-516. https://doi.org/10.1016/C2018-0-00969-X

Martin RW, Middleton PG, O’Donnell KP, 1999: Exciton localization and the Stokes' shift in InGaN epilayers. Applied Physics Letters 74, 263-265. https://doi.org/10.1063/1.123275

Massa GD, Kim H-H, Wheeler RM et al., 2008: Plant productivity in response to LED lighting. HortScience 43, 1951-1956. https://doi.org/10.21273/HORTSCI.43.7.1951
Matsuda R, Ohashi-Kaneko K, Fujiwara K et al., 2004: Photosynthetic characteristics of rice leaves grown under red light with or without supplemental blue light. Plant and Cell Physiology 45, 1870-1874. https://doi.org/10.1093/pcp/pch203

Mims FM, 1992: Sun photometer with light-emitting diodes as spectrally selective detectors. Applied Optics 31, 6965-6967. https://doi.org/10.1364/AO.31.006965

Morrow RC, 2008: LED lighting in horticulture. HortScience 43, 1947-1950. https://doi.org/10.21273/HORTSCI.43.7.1947

Nakamura S, Senoh M, Mukai T, 1993: P-GaN/N-InGaN/ $\mathrm{N}-\mathrm{GaN}$ double-heterostructure blue-light-emitting diodes. Japanese Journal of Applied Physics 32, L8. https://doi.org/10.1143/JJAP.32.L8

Orsini F, Pennisi G, Zulfiqar F et al., 2020: Sustainable use of resources in plant factories with artificial lighting (PFALs). European Journal of Horticultural Science 85, 297-309. 10.17660/eJHS.2020/85.5.1

O'Sullivan CA, Bonnett GD, McIntyre CL et al., 2019: Strategies to improve the productivity, product diversity and profitability of urban agriculture. Agricultural Systems 174, 133-144. https://doi.org/10.1016/j.agsy.2019.05.007

Piovene C, Orsini F, Bosi S et al., 2015: Optimal red:blue ratio in led lighting for nutraceutical indoor horticulture. Scientia Horticulturae 193, 202-208. http://dx.doi.org/10.1016/j.scienta.2015.07.015

RayChaudhuri B, Sen C, 2009: Light emitting diode as sensor for miniature multispectral radiometer. Applied Physics B $\mathbf{9 5}$, 141-144. https://doi.org/10.1007/s00340-009-3439-6

Ryu Y, Baldocchi DD, Verfaillie J et al., 2010: Testing the performance of a novel spectral reflectance sensor, built with light emitting diodes (LEDs), to monitor ecosystem metabolism, structure and function. Agricultural and Forest Meteorology 150, 1597-1606. https://doi.org/10.1016/j.agrformet.2010.08.009

Schubert EF, Kim JK, 2005: Solid-state light sources getting smart. Science 308, 1274-1278. 10.1126/science.1108712

Shibuya T, Takahashi T, Hashimoto S et al., 2019: Effects of overnight radiation with monochromatic far-red and blue light on flower budding and expression of flowering-related and light quality-responsive genes in Eustoma grandiflorum. Journal of Agricultural Meteorology 75, 160-165.

Shockley W, 1949: The theory of p-n junctions in semiconductors and p-n junction transistors. Bell System Technical Journal 28, 435-489. https://doi.org/10.1002/j.1538-7305.1949.tb03645.x

Stukenberg N, Gebauer K, Poehling H-M, 2015: Light emitting diode (LED)-based trapping of the greenhouse whitefly (Trialeurodes vaporariorum). Journal of Applied Entomology 139, 268-279. https://doi.org/10.1111/jen.12172

Vannacci E, Granchi S, Cecchi M et al., 2018: Study of the Light Emitting Diode as a photoreceptor: Spectral and electrical characterization as function of temperature and lighting source. Opto-Electronics Review 26, 201-209. https://doi.org/10.1016/j.opelre.2018.06.001

Vannacci E, Granchi S, Calzolai M et al., 2019: Applications of light emitting diodes as sensors of their own emitted light. Opto-Electronics Review 27, 355-362. https://doi.org/10.1016/j.opelre.2019.11.008

Yang F, Wilkinson M, Austin EJ et al., 1993: Origin of the Stokes shift: A geometrical model of exciton spectra in 2D semiconductors. Physical Review Letters 70, 323-326. https://doi.org/10.1103/PhysRevLett.70.323

Zhang M, Runkle ES, 2019: Regulating flowering and extension growth of poinsettia using red and far-red light-emitting diodes for end-of-day lighting. HortScience 54, 323-327. https://doi.org/10.21273/HORTSCI13630-18 